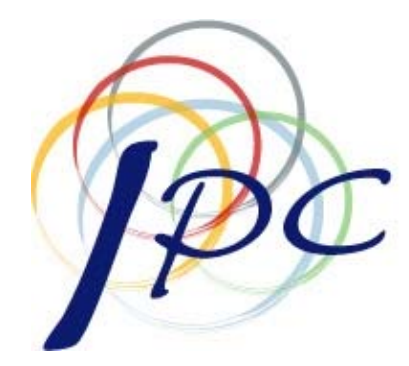

InTERnational Policy Center

Gerald R. Ford School of Public Policy University of Michigan

IPC Working Paper Series Number 19

Issues of Fairness in International Trade Agreements

Andrew G. Brown

Robert M. Stern

September 2006 


\title{
Issues of Fairness in International Trade Agreements
}

\section{Andrew G. Brown, Wellfleet, MA and Robert M. Stern, University of Michigan}

\begin{abstract}
In this paper, we first describe the characteristics of the World Trade Organization (WTO) that are the basis of the framework of the multilateral trading system. We then provide an overview of concepts of fairness in trade agreements. Thereafter, we offer a critique of the efficiency criterion in assessing multilateral trade agreements, taking issue with T.N. Srinivasan's (2006) analysis and then elaborate on our conception of fairness as reflected in agreements covering market access. We also address considerations of distributive justice, in contrast with Srinivasan's contention that distributive justice has no role to play in the design and negotiation of multilateral trade agreements. Finally, we question bilateral trade agreements from the standpoint of fairness, drawing on the example of the U.S. bilateral FTA negotiated in 2005 with Central America and the Dominican Republic.
\end{abstract}

Keywords: Fairness, Equality of Opportunity, Distributive Equity

JEL Classification: D63, F02, F10, F13

September 18, 2006

Address correspondence to:

Andrew G. Brown

P.O. Box 1763

Wellfleet, MA 02667

Tel.: $\quad$ 508-346-0186

E-mail: abrown@c4net
Robert M. Stern

Gerald R. Ford School of Public Policy

University of Michigan

Ann Arbor, MI 48109-3091

Tel.: $\quad$ 734-764-2373

E-mail: rmstern@umich.edu

Fax : 734-763-9181 


\section{Issues of Fairness in International Trade Agreements}

\section{Andrew G. Brown, Wellfleet, MA and Robert M. Stern, University of Michigan}

\section{Introduction}

In Brown and Stern (2005, 2006), we discuss why fairness is a condition of the multilateral trade agreements among governments that form the global trading system. We suggest that fairness can best be considered within the framework of two concepts: equality of opportunity and distributive equity. We observe that the criterion of economic efficiency and welfare maximization is not a primary yardstick of fairness, and though it is relevant in choosing among alternative ways of realizing fairness, it has some significant limitations. In what follows, we discuss the meaning of equality of opportunity and distributive equity that apply to the multilateral commitments that governments make in the global trading system and how these criteria are to be interpreted in the context of bilateral free trade agreements (FTAs).

Srinivasan (2006) has taken issue with our conception of the criteria of equality of opportunity and distributive justice in the design and negotiation of multilateral trade agreements. He argues rather that multilateral trade agreements should be judged on the basis of the principle of welfare maximization coupled, if necessary, with income transfers that may be needed for the gainers from trade liberalization to compensate the losers and still enhance economic welfare. In his view, it may be impossible to devise an acceptable criterion of fairness in trade agreements, essentially because of the difficulty of tying in the interests of a nation state with the interests of the individuals who comprise the nation state.

In what follows, in Section II, we describe the characteristics of the World Trade Organization (WTO) that are the basis of the framework of the multilateral trading system. We then provide an overview of concepts of fairness in trade agreements in Section III. In Section IV, we offer a critique of the efficiency criterion in assessing multilateral trade agreements with reference to Srinivasan's analysis and then elaborate on our conception of fairness as reflected in 
agreements covering market access. In Section V, we address considerations of distributive justice, taking issue with Srinivasan's contention that distributive justice has no role to play in the design and negotiation of multilateral trade agreements. In Section VI, we consider bilateral trade agreements from the standpoint of fairness, drawing on the example of the U.S. bilateral FTA negotiated in 2005 with Central America and the Dominican Republic. Section VII concludes.

\section{The WTO Framework for the Multilateral Trading System}

Srinivasan notes (pp. 4-5), according to GATT (1994, p. 6) that:

"The chapeau or preamble to the agreement to establishing the WTO states the objectives of the parties to the agreement were to raise standards of living, ensure full employment and a large steady growing volume of real income and effective demand, expand production while insuring the optimal use of world resources consistent with sustainable development, protection and preservation of the environment and in a manner responsive to the needs and concerns of parties of different levels of economic development. The parties sought to achieve these objectives 'by entering into reciprocal and mutually advantageous arrangements directed at the substantial reduction of tariffs and other barriers to trade and to the elimination of discriminatory treatment in international trade relations,' and resolved therefore 'to develop an integrated, more viable trading system encompassing the General Agreement on Tariffs and Trade, the results of past trade liberalization efforts, and all a result of the Uruguay Round of Multilateral Trade Negotiations."”

Srinivasan proceeds to note that the objective of the WTO is to promote the public interest, based on the two fundamental principles of neo-classical welfare economics, according to which (p. 7), “.... competitive equilibrium under free trade is globally_Pareto optimal, ....and a free trade allocation that is Pareto Superior to the autarky allocation for consumers in each trading nations exists and can be sustained as a free trade competitive equilibrium using lump sum transfers among domestic residents_only.”

Srinivasan further states (p. 10) that: “The WTO is an intergovernmental_organization, and any agreement that its members conclude for constraining their trade policies will affect the welfare of producers and consumers in each member country. These two facts raise a number of issues including importantly of political economy...,” which need to be addressed. 
In surveying the history of international negotiations and agreements on trade in goods and services, Srinivasan (p.20) clarifies the role and character of multilateral trade negotiations and agreements reached in the GATT/WTO as follows:

"First, MTNs are voluntary and as such, there is a strong presumption that signatories to the agreements find them, on balance, to be worthwhile signing as compared to not signing. Second, any member of the GATT and the WTO can withdraw from it for whatever reason after giving a six-month notice. Thus, any signatory to an agreement concluding a round of MTN sponsored by GATT/WTO, if it later found it wanting, could always withdraw from the GATT/WTO, if it thought that withdrawal was a better option, rather than continuing to be a member and using the mechanisms available to correct any aspect of the agreement that it found wanting."

From the foregoing, there are some central elements of the WTO and international negotiations and agreements on trade that need to be stressed. These include: (1) reciprocity, mutual advantage, and non-discrimination; (2) promotion of the public interest via efficient resource allocation and maximization of economic welfare; and (3) voluntarism in MTNs and signatory country acceptance of negotiated agreements. In the following section, we review the concepts of fairness that we argue are germane to the multilateral trading system, and thereafter address the limitations of economic efficiency and maximization of economic welfare as a guide to fairness.

\section{Concepts of Fairness}

In our view, we take as a premise that, since membership in a system like the GATT/WTO is voluntary, its rules and procedures rest on mutual consent. In the context of discussing fairness, this is a crucial characteristic. That is, unless there is consensus about the fairness of the rules and procedures in the trading system, countries will not abide by them indefinitely. Fairness is therefore an element in the existence and functioning of the system.

Such a system of cooperation is, to be sure, only approximated in reality. Powerful nations are more able to press for the adoption of rules and procedures that suit them, while the weaker nations are more often obliged to compromise. It can be argued that, since participation is 
voluntary, no country need accept the negotiated outcomes if it believes that these run counter to its interests. But that is not necessarily so, since rejection would entail withdrawal from membership in the GATT/WTO altogether. A country would then lose all the rights embodied in the GATT/WTO regime, such as MFN treatment and the protections afforded by the disputesettlement mechanism. Thus, there may be circumstances in which a country may emerge worse off from a round of negotiations, yet to find it has no choice but to accept the worsened status. Nevertheless, it remains true that, if ideas of fairness are seriously and persistently violated, the cooperation on which the system rests will be threatened and the system thereby undermined.

In our view, fairness in the global trading system can best be assessed in terms of two criteria: equality of opportunity and distributive equity. ${ }^{1}$ It should be understood that we do not advance equality of opportunity as a high moral principle. It is an instrumental criterion to be valued for its consequences, namely that it facilitates the reaching of inter-governmental agreements that protect and enhance the mutually advantageous trading system. Distributive equity can also be argued — somewhat more tendentiously — to be an instrumental criterion. That is, in correcting for the disadvantageous initial conditions faced by poorer countries, it is ensuring that all can respond to a legal, or formal, notion of equality of opportunity. For many of us, however, there is also a deontological element in the criterion insofar as we accept it as a moral obligation and do not insist upon it because of its advantages to ourselves.

As will be discussed below, we do not include the yardstick of allocative efficiency as a criterion of fairness. Efficiency is pertinent to the extent to which global resources are being used optimally. But no nation is likely to subscribe willingly to successive trade agreements that leave them worse off, no matter the gain in global welfare. The efficiency yardstick is, however, important in choosing among alternative ways of fulfilling the conditions of fairness. And the

\footnotetext{
${ }^{1}$ Other concepts of fairness include commitments that countries make in the global trading system with regard to supporting rules designed to prevent cheating in market access commitments or to facilitate trade flows, those relating to procedures for the settlement of disputes or the use of trade remedy measures, and those relating to governance of the system. These other concepts are discussed in Brown and Stern (2005, 2006).
} 
analysis of alternatives may in itself alter the perception of fairness that influences agreements. We should nevertheless be aware that the yardstick of efficiency pervades much of the commentary on the global trading system, and - ambiguous though it also is - may tend to overshadow considerations of fairness.

We should also mention that consideration of the micro-foundations of fairness lies beyond the scope of our analysis. As we have already noted, Srinivasan (2006) has been critical of us on this account. Thus, he notes (pp. 20-21) that:

"...defining an aggregate welfare function in the context of bargaining among nation states is conceptually difficult, if not impossible.” Further (p. 23): [The Brown and Stern framework] may seem “... to anthropomorphize nation states but also aggregate diverse nations into 'poor countries' and 'developed countries'. The concepts of social justice, fairness and solidarity among individual citizens within any single nation state raise deep philosophical and measurement issues. [The] authors do not provide any foundation for meaningfully extending these difficult concepts to collectives such as nation states. One could, of course, attempt to define social justice and equity among all human beings, but such a concept has no apparent connections to equity among nation states, whatever it might mean. One could interpret the distributional equity of an agreement to mean, that the distribution of welfare [across all human beings] under the agreement stochastically dominates the distribution prior to the agreement as incorporating justice and equity among all humans. But this is not what [the] authors had in mind."

While Srinivasan's criticism is well taken, it may be overdone. Thus, in a private communication to Srinivasan by Kenneth Arrow (May 19, 2006) on Srinivasan’s (2006) paper that Srinivasan kindly made available to us, Arrow noted that Srinivasan’s

“...remarks on the meaning of equity and fairness reflect many of the relevant considerations. However, they... seem to be mainly carping about the difficulty in defining 'fairness,' in the trade agreement context. It is difficult to give a rigorous definition of almost any concept, particularly a normative criterion, but nevertheless we use normative notions all the time.”

We therefore leave it up to the reader to form his own judgment on the issue of the microfoundations of fairness. In this connection, it should be noted that our analysis is framed in terms of relations among independent nations. Within nations, many groups and individuals also hold varying views about the fairness of the trading system. Anti-globalization advocates, for instance, view the trading system as being dominated by powerful governments and corporations 
whose main concern is to enhance national interests and corporate profits to the possible detriment of the less fortunate within their own societies or the societies of poorer nations. We assume that a trading system deemed to be fair by the participating governments will create opportunities for all to enlarge their trade and to enhance their national economic welfare. How the gain in welfare is distributed within countries is a large matter of domestic public policy that, while immensely important, is not central to our analysis. Internal distribution issues certainly concern individual governments, influence their negotiating stances, and alter their perceptions of fairness. But we are addressing inter-governmental trade relations that are the basis of the GATT/WTO system, and we take the interests of each government's interpretation of its interests as given.

In the following section, we consider the yardstick of efficiency in order to put it into perspective in the discussion of fairness. We then discuss equality of opportunity in market access and thereafter consider what distributive equity means in relation to market access.

\section{The Efficiency Criterion, Equality of Opportunity, and Market Access}

For political leaders and their trade diplomats, bargaining to win gains in market access has been at the core of trade negotiations. For economists, however, this may not conform with notions of rational behavior. Defining rationality as the maximization of utility, gains in market access are an unsatisfactory standard that fails to capture fully the welfare benefits arising from trade negotiations. That is, the focus is largely on the liberalization of export markets and not on the effects of trade liberalization as a whole.

As mentioned above, greater efficiency is defined as a movement toward Pareto optimality, and in the context of international trade, that state would be reached when no country can be made better off without some other being made worse off. If, however, the losing countries can be compensated by the gaining countries, still leaving the latter with some net benefit, this would qualify as an improvement in efficiency. This compensation rule is an 
important qualification in international trade since gains in allocative efficiency made by individual countries may be offset by losses arising from terms-of-trade effects. However, beyond this compensation rule, the efficiency criterion does not concern itself with the distribution among countries of the welfare benefit that accrues from the trade negotiations. It thus appears that, so long as no country gains at the expense of any other, no country has rational grounds for resisting multilateral trade liberalization.

What may seem strange to many observers about the focus on allocative efficiency is that it does not address distributional issues, which as we will discuss below are a central aspect of fairness in multilateral trade agreements. The focus on allocative efficiency implies that the gains accruing to each country are determined, at least in part, by the country's own action in liberalizing its import trade. If it is within a country's own power to enhance its benefit from trade, the question of fairness among countries may not arise. It is true, however, that each country is affected by the others in so far as failure by the others to liberalize deprives it of the benefit of the expansion of its export industries. Thus, the one concern that the efficiency criterion has with the distribution of gains turns on the relative gains that countries make in gaining greater access to export markets.

Though many economists might generally admit that the efficiency criterion does not address the issue of the distribution of benefits among countries, they would still defend its value. They would argue that, in defining the conditions under which optimal output can be realized, it makes a major contribution to the assessment of policy measures affecting the functioning of markets. Thus, most economists unhesitatingly support reductions in trade barriers as positive in their effects. They might admit that, because of the political economy of trade relations, the application of such a yardstick of efficiency to the outcome of multilateral trade negotiations may not be sufficient in its own right. Nonetheless, it seems reasonable that some assessment of the effects of the negotiations on the performance of markets is a relevant part of the overall judgment of the outcome of a multilateral trade agreement. 
But disregard of the distributional issue is not the only criticism that can be leveled against this efficiency criterion, which derives from a theoretical model of the market economy that abstracts from many aspects of reality. Even when accepted on its own limited terms, it has to be qualified by recognition that market failures take place. In the context of international trade, it has long been accepted, for instance, that protection of infant industries on grounds of externalities is, at least in principle, a legitimate exception. Further, still within its own terms of static equilibrium analysis, the criterion disregards the costs of adjustment to a new state of equilibrium that follow from trade liberalization. These can be of no small importance. It is one characteristic of many economies — especially of those in the process of development — that they suffer from major structural rigidities arising from poorly functioning markets and institutional deficiencies. Adjustments to changes in market conditions can take many years, especially in the case of agriculture.

The criterion of efficiency is also vulnerable to major criticism because it derives from static equilibrium analysis. It defines efficiency in terms of optimal resource allocation and not in terms of the long-term rate of growth in output. If efficiency is redefined to include the long term increase in output resulting from productivity growth and resource accumulation, the policy prescriptions derived from static analysis may not remain the same. There is unfortunately much less agreement about the policy prescriptions appropriate for economic growth than for optimum allocative efficiency, so the issue is debatable. It is certainly quite possible that there are large overlaps in the policy measures that would improve both static and dynamic efficiency. It may be the case that measures to improve resource allocation may also foster greater economic growth the spur of greater competition, for instance, or exploitation of economies of scale, or the knowledge spillovers that come from links with international markets. It thus seems quite plausible in reality that there may be substantial fusion of the trade measures affecting both static and dynamic efficiency when trade relations are being considered among economies that are at similar levels of technological advancement, have well functioning markets and comparable, 
supporting market institutions.

But for most developing countries (perhaps leaving aside small countries), whatever the positive effects of foreign trade and investment on economic growth, it seems unexceptional to assert that the pace of such growth depends primarily on the performance of domestic producers. There has to be a body of (private or public) entrepreneurs able and willing to organize new productive enterprises in response to sufficient incentives and supported by a stable framework of legal, financial and technical institutions. But domestic policies, including trade policies, that take account of the need to promote a growing cadre of domestic entrepreneurs, to encourage diversification and to realize the externalities that generate increasing returns, are likely to diverge from those that focus on the improvement of allocative efficiency. The former may argue for discrimination in favor of domestic producers whereas the latter is neutral on the issue.

Thus, even accepting the utilitarian foundation of the criterion of efficiency, it does not provide an unassailably reliable and clear-cut guide to policy. Market failures have to be allowed for, and a dynamic definition does not lead to the same policy prescriptions. But what may be a more fundamental deficiency is the idea expressed by Rawls (1971) that "the greatest good for the greatest number” is not compatible with forms of social cooperation entered into by equals for mutual advantage. That is, all participants in multilateral negotiations expect some benefit and none seek the greatest good for the greatest number. Voluntarism and reciprocity in trade negotiations are thus of primary importance. ${ }^{2}$

Despite the uncertain intellectual basis for the conventional criterion of efficiency, its prescription in support of free trade has a strong visceral attraction for many economists. We suggest that the reason lies not solely in the logic of the equilibrium analysis from which it is deduced but in a broader belief based on two observations, one empirical and one historical. First, it embodies the simple, but irrefutable, truth — so persuasively enunciated by Adam Smith

\footnotetext{
${ }^{2}$ Amartya Sen (1988) has offered an extensive critique of the efficiency criterion. See, for example, his lectures "On Ethics and Economics."
} 
— that specialization raises living standards, and since "the division of labor is limited by the extent of the market," barriers to trade are inherently suspect. Second, it is consistent with the historical observation that capitalist enterprise, operating in ever expanding markets, has appeared to be the most effective way of raising the income and wealth of nations. For many, the outcome appears sufficient justification for the criterion.

\section{Equality of Opportunity and Market Access}

For the developed countries at least, the principles embodied in the GATT/WTO — reciprocity, MFN treatment, and national treatment — appear to have provided a working guide to fairness. The principles have been forged from long historical experience and have proved their value in promoting trade relations. They therefore deserve great respect. However, none of the principles is free from ambiguities or easy to define in operational terms. Perhaps the principle of MFN treatment is the least ambiguous though its clarity is now under heavy attack as the number of bilateral trade agreements, all presented ostensibly as free trade arrangements, have multiplied. ${ }^{3}$ National treatment is also fraught with disagreements about its interpretation and application. We limit ourselves here to the use of reciprocity as a guide to fairness.

\section{Reciprocity}

The notion of reciprocity appears operationally important because it assuages the nationalist sentiment that all states harbor and that could otherwise prevent them from gaining the improved market access that they want for their exports. Evidently, no government, unless convinced of the benefits of unilateral trade liberalization, is willing to be accused of giving away more to other states than it receives. ${ }^{4}$ Indeed, it has sometimes been politically important for trade negotiators to claim at home that the concessions received in multilateral trade negotiations are greater than

\footnotetext{
${ }^{3}$ As we will note below, the relation between these bilateral arrangements and the fairness of the global trading system through the erosion of MFN treatment clearly does harm to the perception of fairness.

${ }^{4}$ There may, however, be other motives for participation in a global trade agreement. Some governments, for instance, may welcome participation because it allows them to overcome internal opposition to the opening up of domestic markets. This might make them less insistent on full reciprocity.
} 
the concessions granted. Were this in some objective sense a reality, trade negotiations might have taken place much more infrequently since they would have amounted to a zero-sum game. But, within the clerisy constituted by the trade negotiators from different nations, this large political obstacle has been surmounted by adoption of equivalence as a conventional basis for mutual concessions.

The convention of reciprocity has undoubtedly played a large role in the history of trade relations. In bilateral trade negotiations, negotiators have often directly compared, product by product, the size of the tariff cuts and the volume of trade involved as indicative of equivalence. But this certainly is not an exact and faithful characterization of multilateral trade negotiations witnessed in the more recent past, as Finger, Reincke and Castro (2002) have demonstrated very clearly for the Uruguay Round. Nonetheless, it can reasonably be argued that, in recent negotiations among the developed countries, a rough sense of equivalence could be perceived to have guided them even if there was no close accounting of the gains in market access. In each of the major areas of negotiation, the mutual concessions among these countries were roughly comparable. In tariffs, for example, though the average reduction was not exactly the same, the differences were not large (since tariff levels were already low). Likewise, in the service industries, what negotiators sought was national treatment in each other's markets, and it could well be argued that, since firms in all these countries were more or less equally able to make gains in the others' markets, the potential gains in market access were comparable. Much the same could also be said of the changes made in rules such as technical barriers to trade, which affect market access.

However, this kind of judgment cannot be so readily made in regard to the outcome of the Uruguay Round negotiations affecting trade relations between the developed and developing countries. There was neither the same symmetry in the different trade measures on which the trade partners made concessions, nor could it be assumed that the supply responses to the reductions in similar measures would be roughly comparable. The most dramatic gain for the 
developing countries was purportedly the agreement gradually to dismantle the Multi-Fiber Arrangement (MFA). In return, these countries undertook to lower or bind their tariffs, remove quotas, open up their service industries to some degree, and abide by new or revised rules for such matters as subsidies, foreign direct investment (FDI), and intellectual property. In some of these areas of negotiation, such as the service industries or the new or revised trade rules, the gains in market access clearly favored the developed countries. Were these offset by a possible excess of gains accruing to the developing countries that arose from the mutual reduction or removal of tariffs and quotas by all countries? It is evidently extremely difficult to form a judgment and all the more difficult if we add in both the financial transfers implied by the agreement on intellectual property rights — though not a market-access issue at all — and the back-loading of the removal of the MFA quotas. Thus, with regard to the relations between developed and developing countries as reflected in the Uruguay Round outcomes, the criterion of equivalence in market access gains seems to recede into a fog of uncertainty.

Does this mean then that the criterion is useless? In our judgment, this does not appear to be so. In the earlier stages of multilateral trade negotiations, at least in relations among themselves, the developed countries have in the past adopted common formulae for tariff reductions and agreed on the inclusion or exclusion of other negotiable items on the basis of expected reciprocal benefits. It is when negotiations advanced to more concrete and specific levels that the attention of negotiators appears to have shifted from the issue of inter-country equivalence to an internal accounting of the political value or cost of the concessions gained and granted. At that point, there is no particular reason to expect any correspondence between the inter-country equivalence implied in the initial framework for negotiations and the political balance sheet drawn up at home. Even so, Finger, Reincke and Castro (2002) found that in the final stages of negotiations on tariff reductions, delegations still sought to assure themselves that all parties had made their "appropriate contributions."

Again, however, the initial usefulness of the criterion appears to have worked out much 
less satisfactorily in the Uruguay Round when relations between developed and developing countries are considered. The large differences among these groups of countries in industrial structures and in inherited trade policies (not to mention disparities in bargaining power) made for substantial differences in the content of the bargains struck. So, compared with the bargain struck among developed industrial countries, there was evidently less comparability in the negotiated changes in measures and more uncertainty about the outcomes measured in terms of the consequent expansion in exports.

Still, understood as rough equivalence, the criterion remains important. It counters the nationalist sentiment that can breed mutual mistrust and impede trade cooperation. For such cooperation, it is important that states perceive themselves as being treated as equal, and independent, entities. In so far as the gains in market access can be measured, there is an objective means of assuring every state that it has been so treated. But it has to be admitted that there is great difficulty in translating the criterion into measurable trade outcomes. It is only expected equality of opportunity, not equality of outcome that can be the basis of negotiations among market economies. And if the outcome does not correspond at all to expectations, the sense of fairness is not fulfilled.

\section{Initial conditions}

Even if equivalent gains in market access could be realized in the rounds of multilateral trade negotiations, this would not assure countries of equality of opportunity in regard to market access. Countries enter into negotiations with many differences in the level and profile of their trade barriers, and equivalent reductions in trade barriers do not eliminate these differences. However, successive rounds of negotiations narrow the absolute differences and may eventually render them unimportant. This has been happening among the developed countries since WWII in nonagricultural goods and has begun more recently in some services.

But between the developed and developing countries, large differences persist. As has 
long been pointed out, there are biases in the trade barriers of developed countries against the exports of developing countries. The most obvious instance is the array of measures that restrict trade in agricultural products. Certain labor-intensive manufactures, most notably textiles and apparel, face relatively high tariffs. Tariff escalation by the degree of processing of primary products likewise appears directed against products in which developing countries have a comparative advantage. That these kinds of barriers introduce an overall bias into the developed countries' MFN trade policies appears to be borne out by the measure of trade restrictiveness constructed by the IMF and World Bank. (see IMF and World Bank, 2004, and Hoekman, 2004).

On the other side of the coin, it is also a fact that, among developing countries, trade barriers on non-agricultural goods and services remain high across-the-board. Over the last twenty years or so, numerous countries have unilaterally lowered their tariffs on manufactures, lessening the disparity in existing trade barriers. Some countries bound all their tariffs during the Uruguay Round but many bound only some. Whether the coverage was complete or not, the great majority set their bound rates at levels that were substantially higher than their current, applied rates. So many countries have accepted only limited formal obligations in granting market access. The gradual lessening of these embedded biases in trade barriers of both developed and developing countries is therefore a condition of realizing fuller equality of opportunity in market access.

\section{Srinivasan's Critique}

Srinivasan takes issue with the contention of Stiglitz and Charlton (2005, pp. 81-85) that WTO negotiations and agreements are lacking in procedural fairness. As he states (pp. 22-23):

"Presumably fairness of procedures or the process of negotiations is not sufficient to ensure the fairness of the agreement resulting from them. Assessing fairness of agreement necessarily involves an assessment of the outcomes or consequences for those affected by it. Leaving aside the meaning of fairness, there is a prior and practical issue of determining the outcomes of the trade agreements. Liberalization of commitments of parties to a trade agreement in effect expand the set of opportunities, in particular by enlarging access to each other's market. But whether the expanded opportunities are availed of depends 
on other factors, many of them domestic, that are not covered by the agreements. This being the case, the actual outcomes could differ from those anticipated in the event that the opportunities are fully availed of."

We agree with Srinivasan on his criticism of Stiglitz and Charlton. But Srinivasan goes on to criticize both the present authors and Stiglitz and Charlton for calling attention to the need to take "initial conditions" into account in evaluating multilateral trade agreements. He is especially critical in this context of the apparent contention of Stiglitz and Charlton that inequality exists between developed and developing countries, and the implication that it may be unfair to ask the developing countries to reduce their tariffs by the same proportion as the developed countries because of the potentially higher adjustment costs involved for the developing countries. We are in agreement with Srinivasan on this point, but, as we have noted, there are some obvious biases in the trade policies of the developed countries that need to be addressed in the course of the trade negotiations on grounds of fairness. Srinivasan calls attention to the fact that developing countries maintain high tariffs against each other, and that there are significant benefits that could be obtained from reducing these intra-developing country barriers. As stated above, we are cognizant of these barriers. We agree with Srinivasan therefore that there is a strong case that these barriers should be reduced.

\section{Distributive Equity and Market Access}

Does fairness demand that equality of opportunity in market access be modified, in some degree, to satisfy distributive equity? There are at least two grounds for supporting this position.

One derives from a sense of moral obligation to the poor. The great disparity in levels of living among countries and the very large numbers of people living in extreme poverty have convinced many that the governments of rich countries have a responsibility to assist the poor countries in alleviating their poverty. The most visible expression of this obligation is the provision of aid. But since foreign trade is widely seen to play a part in economic betterment, it is identified as another means of pursuing the same end. 
It can also be argued that equality in market access will not be realized so long as some countries are unable to take advantages of the opportunities created by negotiations. The global trading system presupposes the operation of freely competitive markets in which firms in the participating countries respond to new opportunities. But a number of poor countries do not yet have such well functioning markets and merit favorable treatment to strengthen their capacity to exploit new opportunities. ${ }^{5}$

But what does distributive equity mean in the context of the global trading system? It is familiarly associated with the redistribution of income or wealth, but that clearly does not apply here. Though some Third World advocates argued otherwise in past decades, the trading system today is not seen as a vehicle for resource transfers. It is an arrangement for promotion of commercial relations among firms and individuals in different countries that are expected to be mutually advantageous. In our view, distributive equity only acquires meaning in this context if the trading system contributes to accelerating the economic development of the poorer countries. This may be accomplished in one, or both, of two ways.

It is through gains in access to foreign markets that the domestic market can be enlarged and that specialization can be enhanced, leading to such possible beneficial consequences for growth as learning, economies of scale, and technological improvements. More controversially, it is also through protection of domestic markets that, at least in the earlier phases of development, domestic firms (whether nationally or foreign owned) can be induced to establish, to expand and eventually to become competitive with their larger, technologically more advanced foreign competitors. But how far individual countries can gain access to other countries' markets and how far they can gain their consent to protect their own markets, are matters that have to be

\footnotetext{
${ }^{5}$ Wealthy countries may, of course, have other motives for assistance to developing countries. They may want to promote development in order to limit uncontrolled immigration across borders, or to combat terrorism, or, more broadly, to exercise political influence. But these do not raise the issue of distributive equity.
} 
settled in their relations with other countries. ${ }^{6}$ Thus, the requirement of distributive equity in the global trading system is presumably that the development of poor countries should be favored through the common pursuit of measures that accord their firms preferred status in their foreign or domestic markets or both.

In practice, developed countries have offered favorable access to their markets through their several non-reciprocal preferential programs. ${ }^{7} \quad$ Under the Generalized System of Preferences (GSP), the developed countries have provided developing countries with preferential access to their markets since the 1970s. In addition, both the U.S. and EU operate other, still more favorable, schemes for particular groups of countries, such as the countries of Sub-Saharan Africa under the U.S. African Growth and Opportunity Act (AGOA) or the EU's Cotonou Agreement that favors the African, Caribbean, and Pacific (ACP) former colonies. Further, the developed countries generally provide still more extensive preferences to the least developed countries. ${ }^{8}$

These preferential schemes have been of some value, though often less than expected. While their product coverage is quite extensive in some schemes, the actual use of these preferences falls far short of their potential use. One possible reason for this lack of use is that exporters have found the transaction costs of the certification process too heavy in relation to the saved preferential margin. A more common speculation is that exporters were unable to comply with rigorous rules of origin. The conclusion we draw is that, while the schemes have surely

\footnotetext{
${ }^{6}$ True, we cannot exclude the fact that countries may independently benefit from unilateral reductions in trade barriers and that, indeed, this may be an integral part of their growth strategy. Thus, viewing trade benefits solely in terms of national economic growth does not necessarily provide a comprehensive definition of all the benefits from trade. But it is part of a comprehensive definition and does raise the issue of equity.

${ }^{7}$ These preferential measures are sometimes discussed as though they were a means of redistributing current income generated by trade to developing countries. A criticism of preferential programs is, for instance, that the rent is sometimes captured by importers in the developed countries. But if the intent of the measure is to promote development, what matters is not the effect on the current distribution of trade income but the effect on production and exports in the developing country. Some long-standing preferential arrangements, however, clearly no longer serve any development purpose and are no more than mechanisms for income transfers. The arrangement covering the exports of a few developing countries under the Sugar Protocol of the EU is an example.

${ }^{8}$ For a review of the literature on the benefits of preferences for developing countries, see Hoekman and Ozden (2006).
} 
benefited individual producers, their impact on the overall export performance of countries is an open question.

Much more controversial is the question whether distributive equity demands that the global trading system should also allow developing countries freedom to apply preferential measures in support of firms within their own domestic markets. Responses turn on the causal beliefs held about the effectiveness of protectionist measures in assisting national development. There is ample empirical evidence that the highly protectionist, import-substituting policies pursued by a number of countries in earlier postwar decades were often detrimental to sustained development. The policies encouraged the emergence of inherently high cost industries, contributed to biases in domestic cost structures that impeded export growth, and sheltered domestic enterprises from competition and the need to innovate. Greater openness has been among the policy measures associated with higher economic growth. However, this criticism of inward-looking policies does not demonstrate that protectionist measures, as part of an array of domestic policies, are ineffective in contributing to the development of emerging countries. The recognition of the value of protection in fostering the establishment of new industries has a long tradition. In providing protection from foreign competition, protection may allow time for new firms to learn and to overcome scale disadvantages.

These differences in causal beliefs are not likely to be resolved any time soon. Practically, the persuasiveness of the one view or the other depends a great deal on the specific circumstances of the individual country under consideration. Countries vary so enormously in their economic size and stage of economic development that any sweeping generalization may justifiably be suspect. This being so, any agreement on how the global trading system can fairly address the issue, is only possible if the differences in causal beliefs are accommodated. This means that the multilateral trade rules should make adequate allowance for the use by countries of protectionist measures that are defensible as developmental policies. 


\section{Srinivasan's Critique}

Srinivasan (pp. 23-24) takes issue with Stiglitz and Charlton in their treatment of distributional

equity. In particular, he notes the contention of Stiglitz and Charlton (p. 76) that:

"Any agreement that differentially hurts developing countries more or benefits the developed countries more (say, as measured by the net gains) should be presumptively viewed as unfair. Indeed, it should be essential that any reform be progressive, i.e., that a larger share of the benefits accrued to the poorer countries.”

“...it is not obvious why the share of benefits from an agreement that accrues to poorer countries necessarily has to rise for it to be fair. Why is an agreement, which delivers a Pareto improvement over the status quo in the sense of benefiting every member of the WTO but in which a large share of the benefits accrue to richer countries unfair? What is the rationale of normalizing net gains by GDP (valued at domestic prices, world prices, purchasing power parities, or what)?”

In Brown and Stern (2005, 2006), we are similarly critical of this contention of Stiglitz and Charlton.

On a related issue, Arrow, in his aforementioned comment, raises the question of what may be meant by the gains from a trade agreement going "more" to developing countries than to the developed countries. That is, does "more" mean a relative or an absolute measure of gain from a trade agreement, and, in this context, what may constitute fairness in the agreement?

As we have noted in earlier discussion, in trade relations, the issue of fairness arises first and foremost in the demands and offers that negotiators make about market access. The prize that negotiators on each side seek is an expected gain in exports (against which they have to weigh the political cost of increased imports). In economic analysis, the expected gain in exports does not measure the expected increase in economic welfare that would ensue from the trade agreement, but we can take it as a rough proxy for the latter. Now, for purposes of illustration, suppose that we have a trade agreement between a large and a small country - say, the United States and Costa Rica - and suppose that the negotiators have exchanged reductions in trade barriers that they both perceive as providing roughly equivalent gains in market access. Both therefore expect that the increase in their exports will be about the same in absolute terms. Costa Rica, being the smaller 
country, will then experience the greater increase in exports relative to GDP. Taking exports as a proxy for economic welfare, it will have the greater relative economic gain.

In terms of gains in market access - which is the negotiators' criterion of fairness -- the gains are equivalent and the trade agreement appears to be fair. However, if relative economic gain is taken as the measure of fairness, then Costa Rica appears to come out winning (though this is only saying that trade is always more important for the smaller economy.) Which measure of fairness is right? Absolute gains in market access or relative gains in economic welfare? If we stay close to the real world, it is the negotiators' concept that surely applies. Fairness concerns relations among nations, and it is the political perception of what is negotiated that counts. But we should stress, as our discussion of distributive equity has made clear, that there is a case for the developed countries to make special efforts to liberalize their import barriers, especially when they reflect built-in impediments that affect developing countries differentially.

\section{Issues of Fairness in Bilateral Free Trade Agreements}

The emphasis in our discussion has been on issues of fairness as applied to multilateral trade agreements in the GATT/WTO contexts. In recent years, it is well known that there has been a proliferation especially of bilateral FTAs. Many of these bilateral FTAs have involved negotiations between large developed countries/regions like the United States, European Union, and Japan vis-à-vis much smaller developing countries. How should we think about fairness then in the context of bilateral FTAs?

Consider, for example, the case of the U.S./Dominican Republic-Central America Free Trade Agreement (DR-CAFTA). As noted, say, from the standpoint of Costa Rica, it may be the case that the gains in market access are equivalent. But Costa Rica could still complain that the agreement was unfair. It could do so on equity grounds that it was a poor country and that the United States had a moral obligation to take account of the disparity in levels of development. 
Now suppose that the United States has actually taken advantage of its superior bargaining power and has won greater gains in market access from Costa Rica than it has conceded to Costa Rica. (This is the reality under the DR-CAFTA agreement that has been described by the United States Trade Representative (USTR) as correcting the "one-way free trade” that the Central American countries formerly enjoyed.) This could be deemed to be fair only if the preferred access that Costa Rica has previously enjoyed in the U.S. market was now judged to be unfair.

However, even if this disregard of the normative criterion of distributional equity was deemed to be a defensible position, consider the consequences of the asymmetric reduction in trade barriers. If negotiators’ expectations are realized, U.S. exports to Costa Rica should initially increase more than Costa Rica's exports to the U.S. In the normal course of events, however, this imbalance would be corrected. Costa Rica’s current account balance would deteriorate, triggering an adjustment process. Domestic unemployment would rise, the exchange rate would depreciate, and domestic expenditure would switch until a new equilibrium was established at a lower level of U.S. exports. The asymmetric reciprocity in trade concessions would not be realized in trade outcomes. U.S. proponents of the agreement could nonetheless argue that it was doing Costa Rica a good turn since it would have moved the country toward greater openness in external trade than might otherwise have been the case. But Costa Rica would have paid a price in adjustment costs in excess of what was needed to realize the final outcome. ${ }^{9}$ Thus, even if the U.S. believed that Costa Rica's formerly preferred access was no longer justifiable, the U.S. could be said to have been acting unfairly because the asymmetry in the negotiated reduction of trade barriers would have imposed excess adjustment costs on Costa Rica. ${ }^{10}$

\footnotetext{
${ }^{9}$ It is noteworthy that Brown, Kiyota, and Stern (2006), in their computational analysis of the DR-CAFTA, find that there may be considerable employment dislocation in the Central American countries as the result of the FTA as compared to very small employment adjustments in the United States.

${ }^{10}$ Note, however, that the same succession of events could happen even if the U.S. and Costa Rica had negotiated equivalent gains in market access. Supply inelasticities in Costa Rica could prevent it from taking advantage of the increased export opportunities. We cover ourselves by saying that we discuss
} 
If we consider the actual DR- CAFTA agreement as it affects Costa Rica, the U.S. very probably makes gains in market access that significantly exceed those won by Costa Rica. In addition to the tariff and quota changes, market access is improved through other actions like the opening up of service sectors, their privatization and deregulation, government procurement, and the streamlining of customs procedures. These changes in access almost entirely benefit the United States. And there are other major matters included in the agreement, not directly relating to market access, which also favor U.S. commercial interests. These include more stringent IP provisions, and investment rules that both remove all restrictions on U.S. investments and protect U.S. interests against "indirect expropriation." In addition, the agreement also responds to American civil society lobbies by including provisions relating to labor rights and environmental standards. ${ }^{11}$

In assessing the DR-CAFTA, is the question of fairness relevant for either the United States or Costa Rica? The reality may be that the United States has used its superior bargaining power to gain a net advantage for its commercial interests and to include conditions in the agreement that placate some lobbyists in U.S. civil society. From a national point of view, the gain in economic welfare is very small. But the agreement has value as an instrument of foreign policy. DR-CAFTA ties countries within the region more closely to the United States, helping to promote more stable governments (and some of the countries have a lengthy history of unstable and dictatorial governments) and to entrench U.S. regional hegemony. The agreement may also be important as another tactical step toward an FTAA.

Granted the foregoing points, however, there are no indications that the U.S. Congress or the U.S. administration has taken anything other than self-regarding concerns into consideration in formulating the DR-CAFTA agreement. Discussions in Congress appear to bear out this

fairness in terms of equality of opportunity, not of outcomes. But negotiators value opportunities in terms of their expected outcomes.)

11 The provisions of U.S. FTAs, which are patterned after those contained in the NAFTA, are noted in Brown, Kiyota, and Stern (2005a,b and 2006). 
preoccupation with maximizing immediate national interest. The larger question of whether the superior American power was being exercised with restraint, in a manner that would sustain a national reputation for fairness in foreign relations, was apparently never raised. Some observers have expressed concern that aspects of the agreement were an unjust abuse of power; pointing to provisions in the agreement - like freer trade in staple foods or the IP conditions - that could worsen the plight of many of the poor and the sick in the Central American countries. Among supporters of the agreement, it was widely believed that the free market thrust of the agreement would undoubtedly bring benefit to the poor countries, and this was used as self-justification for imposing an unfair agreement on small and weak countries.

For Costa Rica and other small FTA members, the problem is to make the best of the circumstances that confront them. They could possibly reject the agreement and risk the displeasure of its powerful neighbor (which, among other things, might withdraw existing preferences); or they can accept the conditions and hope that the benefits are rewarding in the long term. On this latter score, the primary issue is whether closer economic ties with the United States, as set out in the agreement, would accelerate the pace of economic growth by encouraging greater investment, and particularly foreign investment, seeking to take advantage of easier and more secure access to the American market. This would need to compensate for the adjustment costs faced by FTA members, for the loss of autonomy over a range of economic and social issues, and for the obligation to conform a number of national laws, regulations and practices to standards required by the United States.

In the final analysis, it does not seem to make much sense to inject the idea of fairness into an assessment of this agreement and others like it. Many of these FTAs involve countries that are very unequal in power. The conditions are not negotiated on the basis of equivalent exchanges, but are largely stipulated by the powerful country on a take-it-or-leave-it basis. The idea of fairness might still be present if the more powerful country was sufficiently conscience 
stricken to respect reciprocity — in the sense of some equivalence when mutual concessions are taken as a whole. But that does not appear to be the case.

It might be better to say that the conditions laid down by the United States are unjust rather than unfair. Fairness is a form of justice that arises in relations between independent entities. But when one party has the power to impose its will, it seems more appropriate to ask whether it is acting justly.

\section{Conclusion}

In defining fairness in global trade relations, we offer a framework composed of two criteria: equality of opportunity and distributive equity. Equality of opportunity requires reciprocity among countries in the reduction of trade barriers, adherence to MFN treatment, and removing the biases in initial conditions. ${ }^{12}$ Equality of opportunity, however, has to be modified in some degree to allow for distributive equity — understood as the promotion of development. In this framework, the criterion of efficiency is not a primary yardstick of fairness, but it is relevant in choosing among ways in which fairness can be realized.

We have noted that, in market-access negotiations, reciprocity is of most value in realizing fairness. We have argued that, in the context of the global trading system, distributive equity has meaning only in one particular sense, which involves the question of whether the trading system gives preference to the efficient growth of production in the poorer nations through sales in foreign or domestic markets.

At present, the bias in the trade barriers of developed countries against goods and services in which developing countries may have a comparative advantage is only modestly offset by the non-reciprocal preferential arrangements that are in force. However, apart from those that apply to the least developed and other mostly small and poor countries, these preferential

\footnotetext{
${ }^{12}$ It also requires that the rules supporting market access are not only seen as equivalent but are also consistent with national preferences within countries, and that procedural justice is respected in such matters as dispute settlement and the use of trade-remedy measures.
} 
arrangements are not likely to be improved. Developing countries generally would, in any case, probably benefit more from a progressive reduction in the bias in developed countries' trade barriers. If this were accompanied by the embrace of fuller reciprocity in tariff reductions on their part, they would move into a more equal partnership with the developed countries in the global trading system. With the rise of the large, industrially more advanced countries like Brazil, China, India and South Africa as significant trading partners, that would seem the likely course of future events anyway. But many developing countries still have great poverty and are not going to shed their developmental status for many years. As we see it, the WTO rules should fully recognize this status by assuring them the option to use specific developmental measures.

We have also had occasion to question whether fairness can be applied in the context of U.S. bilateral FTAs, such as the DR-CAFTA. These U.S. FTAs tend to be highly asymmetrical, with the likelihood that the U.S. realizes more substantial benefits in comparison to their bilateral FTA trading partners.

\section{References}

Brown, Andrew G. and Robert M. Stern. 2006. "Concepts of Fairness in the Global Trading System,” Pacific Economic Review, forthcoming.

Brown, Andrew G. and Robert M. Stern. 2005. Achieving Fairness in the Doha Development Round,” with Andrew G. Brown, Global Economy Journal, Vol. 5 (4), December 2005.

Brown, Drusilla K., Kozo Kiyota, and Robert M. Stern. 2005a. “Computational Analysis of the Free Trade Area of the Americas (FTAA),” North American Journal of Economics and Finance, August.

Brown, Drusilla K., Kozo Kiyota, and Robert M. Stern. 2005b. “Computational Analysis of the U.S FTAs with Central America, Australia, And Morocco," The World Economy, October. 
Brown, Drusilla K., Kozo Kiyota, and Robert M. Stern. 2006. “An Analysis of a U.S.-SACU Free Trade Agreement,” Research Seminar in International Economics, University of Michigan, Working Paper No. 545 (June).

Finger, Michael J. and Philip Schuler. 2000. "Implementation of Uruguay Round Commitments: The Development Challenge,” The World Economy 23: 511-524.

Finger, Michael J, Ulrich Reincke and Adriana Castro. 2002. "Market Access Bargaining in the Uruguay Round: Rigid or Relaxed Reciprocity?” in Jagdish Bhagwati (ed.), On Going Alone: The Case for Relaxed Reciprocity in Freeing Trade. Cambridge: MIT Press.

GATT. 1994. The Results of the Uruguay Round of Multilateral Trade Negotiations: The Legal Texts. Geneva: GATT Secretariat.

Hoekman, Bernard. 2004. “Dismantling Discrimination against Developing Countries: Access, Rules and Differential Treatment,” Discussion Paper Series No 4694. Centre for Economic Policy Research, London.

Hoekman, Bernard and Caglar Ozden. 2006. “Trade Preferences and Differential Treatment of Developing Countries: A Selective Survey,” in Bernard Hoekman and Caglar Ozden (eds), Trade Preferences and the Trading System. Cheltenham: Edward Elgar Publishers.

International Monetary Fund and World Bank. 2004. Global Monitoring Report. Washington, D.C.

Rawls, John. 1971. The Theory of Justice. Cambridge. MA: Harvard University Press.

Sen, Amartya. 1988. On Ethics and Economics. London and Cambridge, MA: Blackwell.

Srinivasan, T.N. 2006. “The World Trade Organization, Doha Round of Multinational Trade Negotiation and Development,” presentation at festschrift conference for Roger Noll, Stanford University, May 20.

Stiglitz, Joseph and Andrew Charlton. 2005. Fair Trade for All. New York: Oxford University Press. 